\title{
Ethanol Measurement
}

National Cancer Institute

\section{Source}

National Cancer Institute. Ethanol Measurement. NCI Thesaurus. Code C74693.

The determination of the amount of ethanol present in a sample. 